\title{
Analysis-based design provisions for steel storage racks
}

K.J.R. Rasmussen ${ }^{1}$ and B.P. Gilbert ${ }^{2}$

\begin{abstract}
The paper summarises the main new design provisions included in the recently revised Australian Standard for Steel Storage Racks. The Standard features multi-tiered analysis provisions ranging from basic linear-elastic analysis-based provisions to highly advanced integrated design-analysis (GMNIA) provisions which allow the analysis and design to be completed in one step. The GMNIA provisions distinguish between beam-element-based and shell-element-based analysis according to the cross-section slenderness, and provides rules for the imperfections to use for the two types of analysis, including imperfections in the local and distortional buckling modes for the shell-element-based analysis. The selection of the system-based reliability (resistance) factor $\left(\phi_{\mathrm{s}}\right)$ is discussed. The Standard is seen as the most advanced design code of its type presently available for frame-type steel structures. The paper also provides in-depth discussion about the use of linear and nonlinear elastic analysis methods for the design of steel storage racks and how torsion may be considered in determining design capacities while not in the structural analysis.
\end{abstract}

1 Professor, School of Civil Engineering, The University of Sydney, NSW 2006, Australia email: kim.rasmussen@sydney.edu.au (corresponding author)

2 Lecturer, Griffith School of Engineering, Griffith University, QLD 4222, Australia; formerly Ph.D. student, School of Civil Engineering, The University of Sydney, NSW 2006, Australia email: b.gilbert@griffith.edu.au 


\section{Introduction}

Structural analysis programs have significantly increased the productivity of structural engineers over the last 25 years, and led to more efficient, more innovative and more economic designs, particularly in the area of steel structures. Structural analysis models for regular and irregular steel frames can now be produced quickly using preprocessing software, and several types of analysis are available in mainstream software packages. These advances in structural analysis and their incorporation in national standards have provided engineers with incentives and tools for optimising their designs.

However, while robust linear and geometric nonlinear structural analysis programs are now readily available in design offices, they remain largely materially elastic. Consequently, they are to be used in conjunction with structural design standards such as the Australian Steel Structures Standard (AS4100 1998), Eurocode3 (EN1993-1-1 2005) and ANSI/AISC-360 (AISC 2010). From a capability viewpoint, advances in the structural analysis software packages commonly used in design offices have been modest over the last decade.

More significant advances have been made in developing architectural software applications. These now integrate modules for the initial conceptual designs with modules for mature stages of architectural design, which may include structural building elements. There is little doubt that these developments will eventually lead to a seamless integration of architectural design software and structural analysis software. This trend gives impetus to furthering the capability of routinely used structural analysis software to include the features necessary to model the real behaviour of structures, including material nonlinearity (yielding), geometric imperfections, residual stresses etc. Software with this capability is termed "advanced analysis" in the Australian Steel Structures Standard. 
Research institutions have used advanced analysis finite element packages like Abaqus, Ansys, Nastran, Marc and Lusas for several decades and it is now well established that the behaviour of structural steel frames can be very accurately predicted using advanced analysis, provided all features affecting the behaviour are included in the analysis, notably geometric and material nonlinearities as well as imperfections. The literature features a wealth of articles demonstrating that the structural behaviour of members and systems subject to complex buckling modes, (e.g. local, distortional, flexural and flexural-torsional modes) and/or complex material characteristics can be modeled accurately using advanced finite element software.

In view of these advances, when Standards Australia initiated a review of the previous version of the Australian Standard for Steel Storage Racks (AS4084 1993), the standards committee charged with the review decided to include provisions for designing steel storage racks by advanced analysis. This required an articulation of the features required to be modeled when using advanced analysis, notably guidance on the imperfections to include and their magnitudes. The revised standard (AS4084 2012) acknowledges that the analysis may be based on shell element analysis in order to appropriately model the effects of local and distortional buckling and includes provisions for this type of analysis. The standard was published in early 2012.

The revised Standard allows rack to be designed directly by use of advanced analysis or by use of elastic analysis in conjunction with a structural design code. The former method is easier to use in so far that member capacity checks to a structural standard are not required. However, it currently involves more effort when creating the analysis model, which requires geometric imperfections to be included. As the modeling of geometric imperfections is increasingly being specified in national standards, like in the revised Standard AS4084, and research is being undertaken to determine system resistance factors for structural frameworks, it is highly likely that during the next few years, 
automated modules for generating geometric imperfections will be incorporated in commercial structural analysis software. As this happens, the use of advanced analysis for structural design will become increasingly attractive.

While new analysis provisions have been included in the revised Australian Standard for steel storage racks, most of the proposed provisions apply equally to regular steel frame structures in general and are readily adaptable in design specifications for steel structures, such as AS4100, Eurocode3 and AISC-360. However, while these specifications allow the use of geometric and material nonlinear analysis in the design of steel structures, they consider structural reliability at member level through the use of resistance factors in specifying section and member capacity design capacities. In contrast, the revised Standard considers structural reliability at system level and specifies a resistance factor for the structure, thus obviating the need for checking section or member capacities to a design standard. Extending the scope of the revised Standard in terms of its analysis provisions to design specifications for steel structures would require a reliability calibration of appropriate system resistance factors to use for irregular frames with particular attention paid to frames failing in out-of-plane 3D modes.

The objectives of this paper are to highlight the scope of the revised new Australian Standard for steel storage racks, to summarise the new provisions related to advanced analysis and to discuss specific issues related to the modeling and design of steel storage racks.

\section{Advanced Analysis Provisions in Current Steel Structures Standards}

Appendix D of the Australian Steel Structures Standard (AS4100 1998) include provisions for design by advanced analysis. However, these provisions are restricted to frames made from 
compact sections and braced out-of-plane, thus precluding 3D flexural and flexural-torsional failure modes. The provisions also require the section capacity be checked according to the interaction equations of the Standard for combined actions. The Australian provisions are based on research by Clarke et al. (1992; 1993) aimed at developing “distributed plasticity” analysis models.

American research (Ziemian, McGuire et al. 1992; Ziemian and McGuire 2002; Surovek-Maleck and White 2004; White, Surovek et al. 2006) focused on large displacement "plastic hinge" type methods. This research lead to the incorporation of provisions for the design of compact section frames using this type of analysis in the 2005 version of the AISC-360 Specification (AISC 2005). However, while such inelastic geometric nonlinear analysis may be adapted for accurately determining the internal actions in the ultimate limit state, the "Inelastic Analysis" provisions of Appendix 1 of the 2005 AISC-360 Specification required the design to be based on the strength provisions for members under combined actions. They did not allow the ultimate capacity of structural steel frames to be determined directly by advanced analysis. The 2010 version of the AISC-360 Specification relaxes the requirement to check member capacities to the Specification and allows frames to be designed by inelastic analysis, provided members and connections are shown to have adequate ductility and the design (by analysis) has a higher or comparable level of reliability. While these general provisions are liberal, the Specification includes provisions to show that members have adequate ductility, which require cross-sections to be compact and members to be braced laterally so as to ensure failure by in-plane bending.

The European analysis provisions (EN1993-1-1 2005) are based on early research by Horne (1985), Nethercot (2000) and Davies (2002). They implicitly assume $1^{\text {st }}$ or $2^{\text {nd }}$ order elastic analysis. More recent provisions are included in Annex C of Part 1.5 of Eurocode3 (EN1993-1-5 2006), which provide guidance on the requirements for geometric and material nonlinear analysis for plated structures. 


\section{Analysis Provisions in the Revised Australian Standard for Steel Storage Racks}

\section{General}

In preparing the revised Standard for Steel Storage Racks, the Standards Committee considered the provisions of the previous Australian Standard for Steel Storage Racks (AS4084 1993), the American Rack Manufacturers Association Specification (RMI 2008) and the European Steel Storage Rack Specification (EN15512 2009). The Committee decided to primarily base the provisions for structural modeling and analysis on the European Specification EN15512 which contains the most advanced modeling provisions of the three specifications. These provisions are further developed in the revised Australian Standard.

Storage racks are predominantly built from cold-formed steel, although when supporting particularly heavy loads, they may be built from hot-rolled steel or tubular sections which may be hot-rolled or cold-formed. The revised Standard AS4084 contains provisions for racks made from both cold-formed and hot-rolled members, and the design of both types of members is discussed in this paper.

The main structural members of steel storage rack frames are uprights and pallet beams. While pallet beams brace uprights and provide stiffness against down-aisle buckling through semi-rigid connections to uprights, the most critical members of a rack structure are the uprights, which are usually made from cold-formed singly symmetric open perforated sections. They are the members most affected by instability, including local buckling, distortional buckling and member flexural and flexural-torsional buckling. In the case of hot-rolled or tubular uprights, the cross-section is 
usually doubly symmetric and does not contain perforations, except near connection points. The buckling modes of hot-rolled or tubular uprights are usually limited to local and member flexural modes.

Steel storage racks may be braced or unbraced in the down-aisle direction. When braced, the spine bracing is accompanied with plan bracing, as shown in Fig. 1, to also provide down-aisle bracing of the front row of uprights. The down-aisle buckling capacity is affected by the stiffness of the semirigid connectors (joints) between uprights and pallet beams, and the semi-rigid stiffness of the base plate connection between the upright and floor, of which the latter is dependent on the axial force in the upright. The stiffness of these joints can be determined according to the testing provisions of the revised Australian standard, which are mainly based on those of the European Standard for steel storage racks EN15512 (2009).

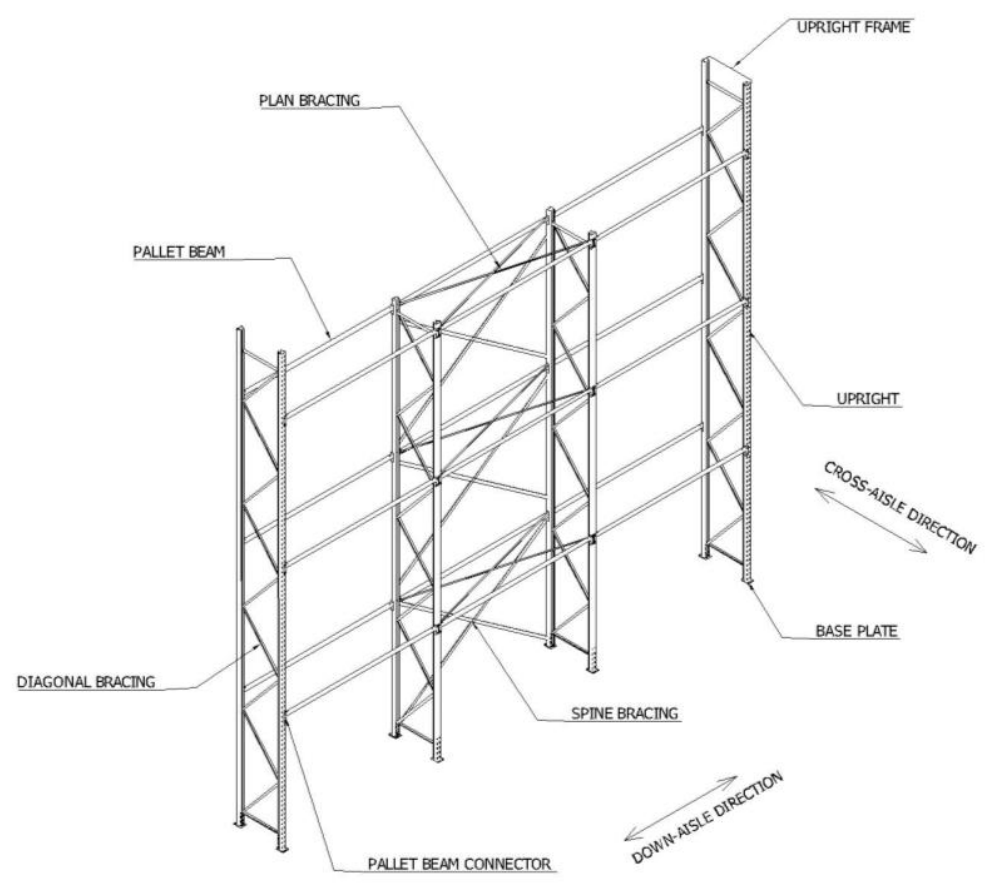

Figure 1. Bracing in steel storage racks. 
The upright frames are usually braced in the cross-aisle direction using diagonal frame bracing, as shown in Fig. 1. Popularly, the brace members are bolted between the flanges of singly symmetric uprights, leading to flexibility and possible looseness in the joints. The stiffness of the upright frames is affected by this flexibility and the revised Standard therefore requires the shear stiffness of the upright frame to be determined by testing. The revised standard contains provisions for the shear stiffness test which are based on those of EN15512, as well as provisions for a new test arrangement based on Australian research (Gilbert 2009; Gilbert and Rasmussen 2011).

\section{Analysis Types}

There is little consistency in the literature in the definitions of the various types of analysis. However, a logical and coherent naming convention was introduced in Part 6 of Eurocode3 (EN1993-1-6 2007) which has also been adopted in the revised standard for steel storage racks. The revised standard features the following analysis types:

LA Linear (elastic) analysis

LBA Linear buckling analysis

GNA Geometric nonlinear analysis

GMNIA Geometric and material nonlinear analysis with imperfections

The latter, often referred to as "advanced analysis", incorporates the dominant nonlinear effects and is capable of accurately predicting the behaviour and strength of structural steel frames. The revised Standard considers two types of GMNIA, one (GMNIAc) assuming the cross-sections is compact and based on beam elements, and one (GMNIAs) assuming the cross-section is non-compact (or slender) and based on full discretisation of members into finite strips or finite elements.

In the cases of LA, LBA, GNA and GMNIAc, the structural analysis may be assumed to be based on beam elements. The structural model may be $2 \mathrm{D}$ or $3 \mathrm{D}$ and may consider torsion, although most 
analyses at present do not consider torsion, particularly not warping torsion. A design may also require several types of analysis to be carried out, e.g. LA and LBA. Thus, there are potentially a large number of possible combinations of structural analyses. However, from a practical viewpoint, it may be assumed that when several types of analysis are employed in a given design, they will be based on the same structural model. Typically, if GNA is employed in conjunction with LBA, it may be assumed that if the GNA is 2D, then so is the LBA, and that if the GNA does not consider torsion, then neither does the LBA.

The requirements for each method of analysis in regard to geometric and material modeling are detailed in Table 1. 
Table 1. Analysis requirements

\begin{tabular}{|c|c|c|c|c|}
\hline Analysis & Material & $\begin{array}{c}\text { Member } \\
\text { imperfection }\end{array}$ & $\begin{array}{c}\text { Frame } \\
\text { imperfection }\end{array}$ & Basis of structural analysis \\
\hline LA Ela & & No & $\begin{array}{l}\text { Out-of-plumb } b^{2} \text { or } \\
\text { equivalent } \\
\text { horizontal forces }\end{array}$ & $\begin{array}{l}\text { Equilibrium is obta ined in t he o riginal (undeformed) fram e configuration, (i.e., th e } \\
\text { displacements are assumed infinitesimal). } \\
\text { The analysis may be based on prismatic beam-elements. } \\
\text { Gross cross-section properties may be used ignoring perforations. }\end{array}$ \\
\hline GNA Ela & stic & No & $\begin{array}{l}\text { Out-of-plumb }{ }^{2} \text { or } \\
\text { equivalent } \\
\text { horizontal forces }\end{array}$ & $\begin{array}{l}\text { Equilibrium is obtained in the deformed frame configuration. } \\
\text { The analysis may be based on prismatic beam-elements. } \\
\text { The analysis may, or may not, con sider t orsional ( } t \text { wist) rot ations and torsional internal } \\
\text { actions. } \\
\text { Gross cross-section properties may be used ignoring perforations. }\end{array}$ \\
\hline LBA Ela & stic & No & $\begin{array}{l}\text { Out-of-plumb }{ }^{2} \text { or } \\
\text { equivalent } \\
\text { horizontal forces }\end{array}$ & $\begin{array}{l}\text { The pre-buckling internal actions may be obtained from LA. } \\
\text { The analysis may, or may not, con sider t orsional ( } \mathrm{t} \text { wist) rot ations and torsional internal } \\
\text { actions. } \\
\text { Gross cross-section properties may be used ignoring perforations. }\end{array}$ \\
\hline $\begin{array}{l}\text { GMNIAc } \\
\text { and } \\
\text { GMNIAs }\end{array}$ & Inelastic & Yes $^{1}$ & $\begin{array}{l}\text { Out-of-plumb }{ }^{2} \text { or } \\
\text { equivalent } \\
\text { horizontal forces }\end{array}$ & $\begin{array}{l}\text { Equilibrium is obtained in the deformed frame configuration. } \\
\text { The plasticity modelling shall be based on flow theory. } \\
\text { The modelling of the non linear s tress-strain relationship s hall be based o n recogn ised } \\
\text { models for hot-rolled or cold-formed steel, as appropriate. } \\
\text { Residual s tresses s hall b e m odelled directly or indi rectly (e.g. thr ough the stress-strain } \\
\text { curve). } \\
\text { Type c-analysis: } \\
\text { The cross-section is c ompact in accordance wi th AS } 4100 \text { an d non-perforated except at } \\
\text { connection points. } \\
\text { The analysis may be based on prismatic beam-elements. } \\
\text { The analysis sh all consider to rsional ( } \mathrm{t} \text { wist) rotations and t orsional internal actions, } \\
\text { including w arping torsion, unless fully laterally restrained as per Cl auses } 5.3 \text { an d } 5.4 \text { of } \\
\text { AS4100. } \\
\text { Type s-analysis: } \\
\text { The cross-section is slender according to AS4100 or cold-formed. } \\
\text { The an alysis is based on dis cretisation of pallet beams an d up rights into s hell finite } \\
\text { elements or finite strips modeling perforations. } \\
\text { The analysis incorporates local and distortional geometric imperfections }{ }^{4} \text {. }\end{array}$ \\
\hline
\end{tabular}

NOTES:

1 Member geometric imperfections shall be modelled in accordance with Section 3.3 .

2 Out-of-plumb shall be modelled in accordance with Section 3.3.

3 Equivalent horizontal forces shall be determined in accordance with Section 3.3.

4 Local and distortional geometric imperfections shall be determined in accordance with Section 3.3. 


\section{Frame Imperfection}

The down-aisle and cross-aisle stability strengths are reduced by out-of-plumb, shown as $\varphi_{\mathrm{i}}$ in Fig. 2a for down-aisle imperfections, and henceforth referred to as "frame imperfection". While frame imperfections can be incorporated in the geometry of the structural model, it is usually more convenient to construct the model assuming vertical uprights and incorporate the effect of frame imperfections by means of notional horizontal forces adjusted to provide the same $1^{\text {st }}$ order base moments as those the combinations of out-of-plumb and vertical pallet loads produce, as shown in Fig 2b. Out-of-plumb is modeled as notional horizontal forces irrespective of the type of structural analysis in the revised Standard.

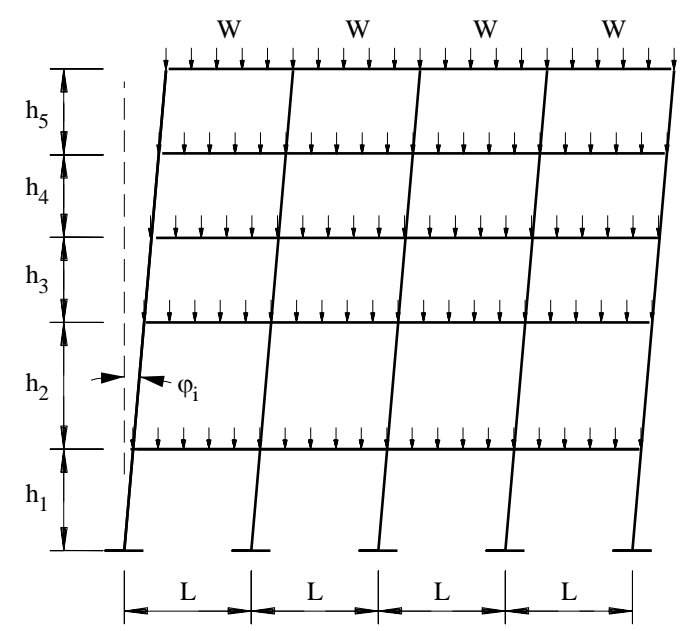

(a) Typical unbraced rack showing initial out of plumb $\left(\varphi_{\mathrm{i}}\right)$

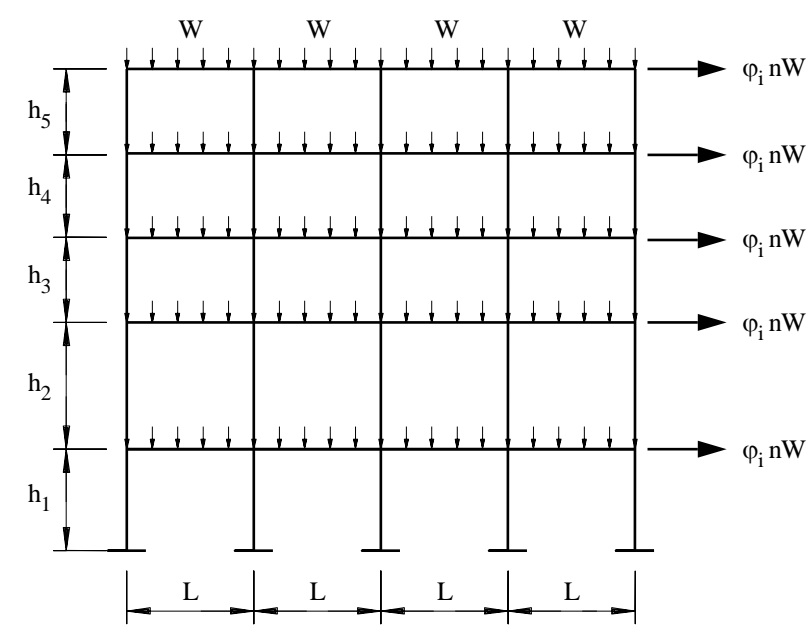

(b) Equivalent loading system for the unbraced rack

Figure 2. Frame imperfection (out-of-plumb) and notional horizontal forces (unbraced frames)

Out-of-plumb is derived from the lack of verticality arising during erection $\left(\varphi_{\mathrm{s}}\right)$ and the looseness of the pallet beam to upright connector $\left(\varphi_{l}\right)$. Testing provisions are included in the revised Standard for determining the latter. 
The frame imperfections $\left(\varphi_{i}\right)$ for unbraced frames specified in the previous Australian Standard for Steel Storage Racks (AS4084 1993), the American Rack Manufacturers Association Specification (RMI 2008) and the European Steel Storage Rack Specification (EN15512 2009) are summarised in Table 2. The previous Australian Standard (AS4084 1993) specified three tolerance grades and different frame imperfections for each grade, as shown in Table 3. The frame imperfection in the previous Australian Standard was a function of the number of bays. The Australian and European specifications add upright-to-pallet-beam connector looseness $\left(\varphi_{l}\right)$ to the frame imperfection, while the American Specification does not. Figure 3 shows the frame imperfection $\left(\varphi_{\mathrm{i}}\right)$ of the previous Australian, current European and current American specifications as a function of the number of bays $(n)$ for two values of connector looseness $\left(\varphi_{l}=0.0025\right.$ and $\left.\varphi_{l}=0\right)$.

Table 2: Frame imperfection for unbraced frames specified in the current Australian (AS4084), European (EN15512) and American (RMI) specifications; down-aisle direction only.

\begin{tabular}{|l|l|}
\hline Specification & $\varphi_{\mathrm{i}}$ \\
\hline AS4084 & $\varphi_{\mathrm{i}}=1 / 2 \psi_{0}(1+1 / \mathrm{n})+\varphi_{l}$ \\
& $\psi_{0}=0.01$ (Tolerance grade I), 0.007 (Tolerance grade II) \\
& and 0.005 (Tolerance grade III) \\
& No connector looseness test: $\varphi_{l}=0.01$ \\
& Range $\left(\varphi_{l \min }=0 ; \varphi_{l \max }=0.01\right): 0.0025 \leq \varphi_{\mathrm{i}} \leq 0.02$ \\
\hline EN15512 & $\varphi_{\mathrm{i}}=\varphi_{\mathrm{s}}+\varphi_{l}$ \\
& $\varphi_{\mathrm{s}}=1 / 350=0.003$ \\
& Range $\left(\varphi_{l \min }=0 ; \varphi_{\operatorname{lmax}}=0.01\right): 0.003 \leq \varphi_{\mathrm{i}} \leq 0.013$ \\
\hline RMI & $\varphi_{\mathrm{i}}=1 / 240=0.0042$ \\
\hline
\end{tabular}

Table 3: Tolerance grade in the current Australian (AS4084)

\begin{tabular}{cll}
\hline Tolerance grade & Type of unit load handling equipment & Maximum allowed out-of-plumb (down-aisle) \\
\hline \multirow{2}{*}{ I } & $\begin{array}{l}\text { Manually operated equipment guided by } \\
\text { operator (e.g., wide and narrow aisles) }\end{array}$ & $1 / 500$ \\
\hline \multirow{2}{*}{ II } & $\begin{array}{l}\text { Manually operated equipment guided by } \\
\text { electrical or mechanical devices (e.g., } \\
\text { very narrow aisle) }\end{array}$ & $1 / 750$ \\
\hline & $\begin{array}{l}\text { Fully automatic operated equipment } \\
\text { guided by electrical or mechanical devices } \\
\text { (e.g., crane installation) }\end{array}$ & $1 / 1000$ \\
\hline
\end{tabular}

It follows from Fig. $3 b$ that the frame imperfections of the three specifications are close for $n \geq 5$ and no connector looseness. AS4084 Tolerance Grade II most closely matches the European and American specifications for this case. When substantial connector looseness is present, the frame 
imperfections specified in the Australian and European specifications are significantly greater than that specified by the American specification, as shown in Fig 3(a).
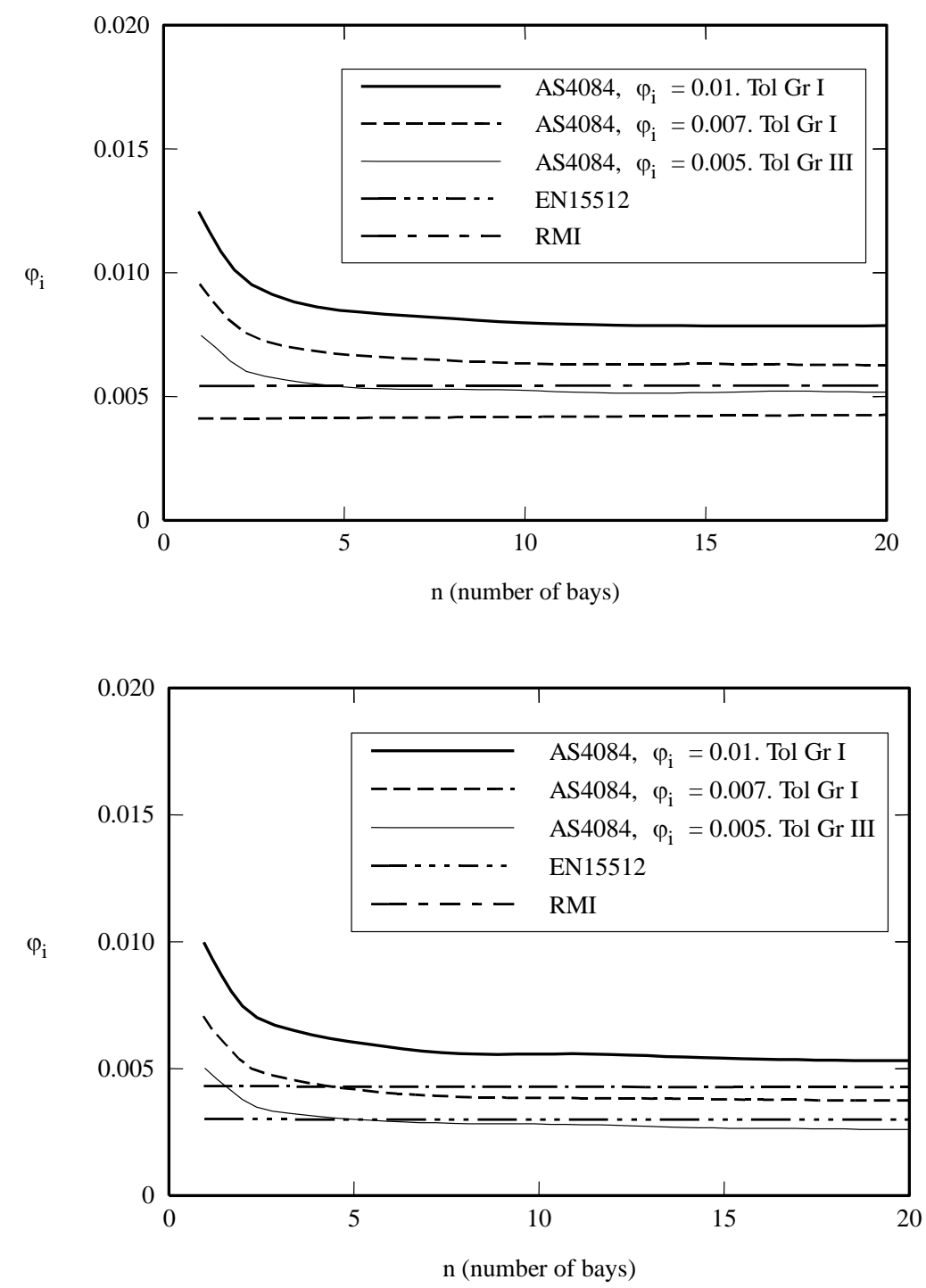

Figure 3: Frame imperfection (out-of-plumb) $\varphi_{\mathrm{i}}$, down-aisle direction only; (a) $\varphi_{l}=0.025$, (b) $\varphi$ ${ }_{l}=0$

It can be seen from Fig. 3 that the number of bays $(n)$ only significantly changes the frame imperfection $\left(\varphi_{\mathrm{i}}\right)$ for $n<5$; a situation of little practical significance. Consequently, the revised Standard adopts the expression for the frame imperfection given in the European Specification,

$$
\varphi_{i}=\varphi_{s}+\varphi_{l}
$$

where $\varphi_{l}$ is the connector looseness to be obtained from tests, or taken as $\varphi_{l}=0.01$ if no test is performed, and $\varphi_{\mathrm{s}}$ is the out-of-plumb erection tolerance shown in Table 3. The revised Standard imposes a specific requirement of $\varphi_{s} \geq 1 / 250$ for GNA which is greater than the requirement of $\varphi_{s} \geq$ 
1/350 of the European Specification. This increased requirement for GNA is incorporated to ensure that sufficient bending moment develops in uprights with dominating axial forces. The requirement is a substitution for the requirement in Clause 8.4.2.2 of AS4100, which stipulates a separate check of the compression member capacity, including the determination of the effective length of the upright. Such requirement is not included in the revised Standard.

The out-of-plumb for braced frames (both the down-aisle and cross-aisle directions) is the same in the revised Standard as that specified in EN15512,

$$
\varphi_{i}=\sqrt{\left(\frac{1}{2}+\frac{1}{n_{\mathrm{f}}}\right)} 2 \varphi_{\mathrm{s}}
$$

where, $\varphi_{i} \leq 2 \varphi_{s}$ and $\varphi_{s} \geq 1 / 500$, and, in the down-aisle direction, $n_{\mathrm{f}}$ is equal to the number of upright frames in one row of bays, and, in the cross-aisle direction, $n_{\mathrm{f}}$ shall be taken as the number of upright frames connected together (e.g., by top ties, run spacers or by intermediate floors) and acting together.

\section{Member Imperfection}

The effects of member imperfection must be considered in the design, either by direct or indirect modeling in the structural analysis or by the use of strength curves in the design strength check. When using LA or GNA, member imperfections are not required to be incorporated in the structural model as their effect is accounted for by the use of column and beam strength curves in determining the member design capacities $\left(N_{\mathrm{c}}, M_{\mathrm{bx}}, M_{\mathrm{by}}\right)$.

When GMNIA structural analysis is used for determining internal actions, geometric imperfections of uprights need to be included in the structural model. The revised Standard suggests the following methods for implementing member imperfections: 
1. by performing an LBA with restraints to prevent sway, scaling the buckling mode to an amplitude of $\delta_{0}$, and superimposing the scaled buckling mode onto the perfect straightmember geometry, or

2. by off-setting nodes relative to the straight member geometry by $\delta_{0}$. In this case, recognising that failure of the frame inevitably occurs mainly by buckling of uprights in the lower two storeys, it is sufficient to introduce geometric imperfections in the uprights of these storeys only. It is also usually sufficient to introduce two additional nodes per member as shown in Fig. 4.

The magnitude of the member geometric imperfection shall be in accordance with the maximum allowable erection member out-of-straightness, typically $h / 1000$ as per AS4100 where $h$ is the length of the member, or the damage of uprights tolerated during service. The damage levels tolerated in the revised Standard are $\delta_{0}=h / 200$ and $\delta_{0}=h / 333$ for the down-aisle and cross-aisle directions, respectively. These damage levels are historical and were retained in the revised Standard at the request of industry representatives. They are not consistent with the design provisions of most structural steel design standards, including the Australian Standards for Steel Structures (AS4100 1998) and Cold-formed Steel Structures (AS/NZS4600 2005) which implicitly assume a maximum member-of-straightness of $h / 1000$.

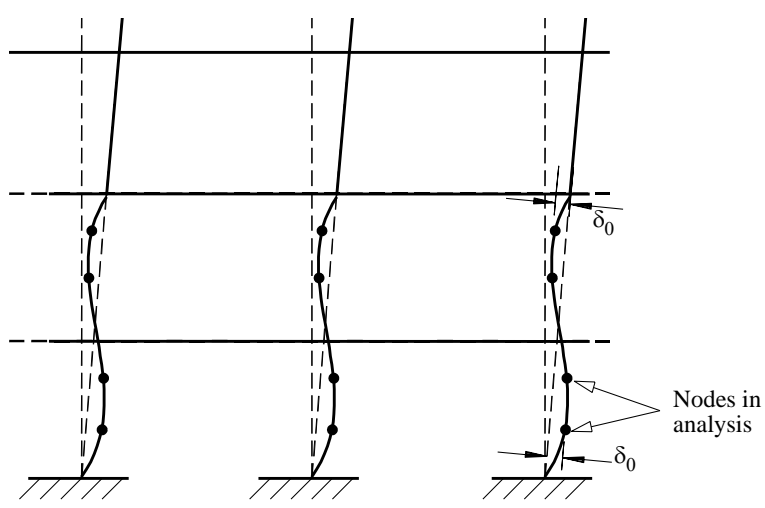

Figure 4: Modeling of member imperfection. 
Alternatively, the effects of geometric member imperfections may be implicitly accounted for by using a reduced flexural rigidity,

$$
E I^{*}=0.8 E I
$$

for all members and connections. This provision originates from the AISC-360 Specification (AISC 2010), which, in lieu of modeling member imperfections, allows the flexural rigidity ( $E I)$ to be reduced as per,

$$
E I^{*}= \begin{cases}0.8 E I & \frac{N^{*}}{N_{y}} \leq 0.5 \\ 0.8 E I\left[4 \frac{N^{*}}{N_{y}}\left(1-\frac{N^{*}}{N_{y}}\right)\right] & \frac{N^{*}}{N_{y}}>0.5\end{cases}
$$

where $N^{*}$ is the design axial force and $N_{\mathrm{y}}=A f_{\mathrm{y}}$ is the squash load. This provisions was also included in the North American Specification for Cold-formed Steel Structures (NAS 2007). The square bracket in Equation (4) accounts for $2^{\text {nd }}$ order effects caused by yielding. While this yieldinginduced reduction of $E I$ may be required for hot-rolled steel structural frames, cold-formed steel racks are unlikely to be greatly influenced by such $2^{\text {nd }}$ order effects, and hence, for cold-formed racks, the reduction of $E I$ may be taken simply as $E I^{*}=0.8 E I$. Studies by Sarawit and Pekoz (2006) support this approach, which has also been adopted in the revised Standard.

\section{Local and Distortional Cross-section Imperfections}

In GMNIAs of slender sections, the strength may be affected by local and/or distortional buckling of the cross-section. In this case, it is required to incorporate geometric imperfections to trigger these modes of buckling. This is usually most conveniently achieved by superimposing geometric imperfections in the shapes of the local and distortional buckling modes onto the perfect geometry. The local and distortional buckling modes may be determined by conducting an LBA with appropriate restraints to suppress frame and/or member buckling and by varying the thickness of the cross-section to switch between local and distortional buckling modes. Supplementary software, 
such as Thinwall (Papangelis and Hancock 1995) or CUFSM (Schafer 2008), may be employed to determine the local and distortional buckling loads and buckling modes.

Research on cold-formed structural members (Yang and Hancock, 2004, 2006) has shown that the magnitude of local geometric imperfections may be determined with reasonable accuracy using the Walker expression (Walker 1975), i.e. the magnitude of the local geometric imperfection may be determined from

$$
s_{o l}=0.3 t \sqrt{\frac{f_{y}}{f_{o l}}}
$$

where $t$ is the thickness, $f_{\mathrm{y}}$ the yield stress and $f_{\mathrm{ol}}$ the elastic local buckling stress of the cross-section as determined from a rational analysis. While the Walker expression was originally derived for local imperfections, it also provides reasonably accurate design strength predictions when applied to distortional buckling (Lecce and Rasmussen 2006), i.e. the magnitude of the distortional buckling imperfection may be determined from

$$
s_{\text {od }}=0.3 t \sqrt{\frac{f_{y}}{f_{o d}}}
$$

where $f_{\text {od }}$ is the elastic distortional buckling stress of the cross-section as determined from rational analysis. Figures 5(a) and 5(b) show the definitions of the magnitudes of local and distortional geometric imperfections respectively. The revised Standard specifies Equations (5-6) for the magnitudes of the local and distortional geometric imperfections, respectively.

The revised Standard requires residual stresses to be modeled directly or indirectly (e.g. through the stress-strain curve) in GMNIA. The Standard does not contain specific provisions for the modeling of residual stresses, whereas it is expected that the Commentary of the Standard will contain such more detailed guidance. It is generally accepted that through-thickness residual stresses lead to a gradual transition from the linear range to the yield plateau in tensile coupon tests and that they can 
be accounted for by modeling the gradual transition when specifying material properties in GMNIA. Membrane residual stresses need to be modeled directly, particularly for the design of storage racks built from hot-rolled or fabricated sections. While cold-formed sections also feature membrane residual stresses arising primarily from the plastic forming process, they are relatively small in magnitude and their effect is likely to off-set by the beneficial enhancement of strength of the corner properties arising from plastic working, which is usually not otherwise accounted for in the design of cold-formed rack structures.
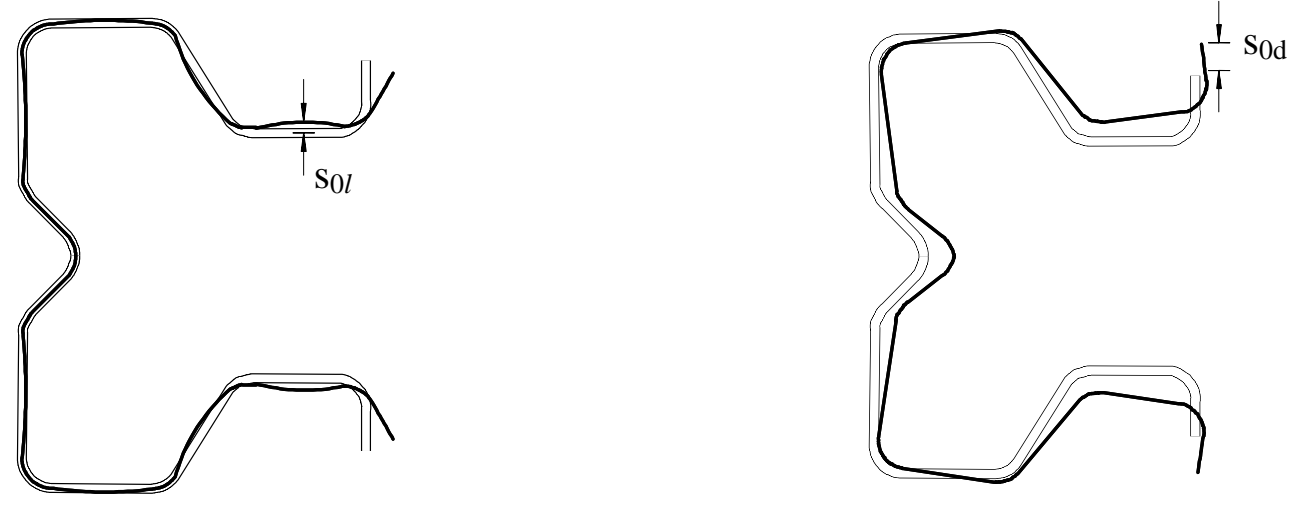
a) Local geometric imperfection
b) Distortional geometric imperfection

Figure 5: Cross-sectional geometric imperfections

\section{Design Provisions for (Singly Symmetric) Cold-formed Steel Uprights}

\section{General}

The revised Standard contains design provisions for all components of rack frames, including uprights, pallet beams, beam-upright connections and base plate connections. However, this paper focuses on the design of uprights because of the greater difficulty they present in terms of geometric shape and propensity to buckling. 
The design of uprights is intrinsically linked to the method of structural analysis underpinning the design. If based on LA, the $1^{\text {st }}$ order bending moments need to be amplified to account for the additional moments produced by displacements. When based on GNA or LA with moment amplification, the member strength is determined using the interaction equations of structural steel design standards, which in turn require the axial and flexural member strengths to be calculated according to the standard, thus accounting for the effect of yielding and combined actions. When based on GMNIA, $2^{\text {nd }}$ order geometric effects and yielding are accounted for, and the ultimate strength of the frame is determined directly. In this case, there is no need for checking the member strength according to a structural design standard, except that a resistance factor $\left(\phi_{\mathrm{s}}\right)$ for the frame is required to be applied to the ultimate load capacity, as discussed in Section GMNIAc following.

\section{Member Buckling Modes in Bending and Compression}

Singly symmetric open sections are particularly prone to flexural-torsional buckling when subjected to compression and bending. Assuming the symmetry axis is the $\mathrm{x}$-axis, in compression, the elastic modes of buckling are the flexural buckling mode about the y-axis (buckling stress $f_{\text {oy }}$ ) and the flexural-torsional buckling mode about the $\mathrm{x}$ - and z-axes (buckling stress $f_{\text {oxz }}$ ).

In bending, when bent about the y-axis, the critical mode is a flexural-torsional mode, irrespective of whether bending induces compression or tension at the free edges of the flanges. This mode needs to be considered in design when $I_{\mathrm{y}}>I_{\mathrm{x}}$. When bent about the $\mathrm{x}$-axis, the critical mode is also a flexural-torsional mode. This mode needs to be considered in design when $I_{\mathrm{x}}>I_{\mathrm{y}}$.

\section{LA and GNA}

Flexure only in LA and GNA (Torsion not Considered) 
In the case of LA, the bending moments $\left(M_{\mathrm{x}}{ }^{*}, M_{\mathrm{y}}{ }^{*}\right)$ must be amplified to account for $2^{\text {nd }}$ order effects. According to the revised Standard, this may be achieved using an LBA to determine the elastic buckling load $\left(N_{\mathrm{cr}}\right)$ of the member, and then multiplying the first-order bending moments by the amplification factor, which in the revised Standard is specified as

$$
\frac{N_{c r}}{N_{c r}-N^{*}} \quad \text { or } \quad \frac{1}{1-1 / \lambda_{c r}}
$$

where $\lambda_{\text {cr }}$ is the load factor obtained from the LBA when applying limit states actions.

It may be assumed that when the analysis does not consider torsion, the structural model is $2 \mathrm{D}$, or, if a 3D model is constructed, restraints are imposed to confine displacements to occur in a single plane at a time, not considering torsion. (Current specifications for racks encourage this type of approach by allowing the down- and cross-aisle analyses to be conducted independently, although with the emerging ready access to $3 \mathrm{D}$ analysis software, there is no need to encourage such $2 \mathrm{D}$ design practice). Thus, distinct load factors $\left(\lambda_{c r}\right)$ and amplification factors are obtained for the down- and cross-aisle directions.

For design based on separate down- and cross-aisle analyses, the effect of combined actions is accounted for using the interaction equations,

$$
\frac{N^{*}}{\phi_{c} N_{c}}+\frac{M_{x}^{*}}{\phi_{b} M_{b x}} \leq 1 \quad \text { and } \quad \frac{N^{*}}{\phi_{c} N_{c}}+\frac{M_{y}^{*}}{\phi_{b} M_{b y}} \leq 1
$$

where $\left(M_{\mathrm{x}}{ }^{*}, M_{\mathrm{y}}{ }^{*}\right)$ are maximum design actions in the span obtained from GNA, or amplified design actions based on LA, $\left(M_{\mathrm{bx}}, M_{\mathrm{by}}\right)$ are nominal member flexural capacities, which account for flexural-torsional, local and distortional buckling, $\left(\phi_{\mathrm{c}}, \phi_{\mathrm{c}}\right)$ are resistance factors for compression and bending, and $N_{\mathrm{c}}$ is the appropriate nominal compression member capacity ( $N_{\mathrm{cx}}$ or $\left.N_{\mathrm{cy}}\right)$, which accounts for flexural, flexural-torsional, local and distortional buckling. 
In certain situations, when considering failure in one direction, the distribution of pallet loads or eccentricities may induce bending in the perpendicular direction, thus leading to bi-axial loading of the uprights. In this case, the interaction equation for biaxial bending is used to determine the member strength,

$$
\frac{N^{*}}{\phi_{c} N_{c}}+\frac{M_{x}^{*}}{\phi_{b} M_{b x}}+\frac{M_{y}^{*}}{\phi_{b} M_{b y}} \leq 1
$$

In determining the compression capacity $\left(N_{\mathrm{c}}\right)$, the effective length for flexural buckling under axial load shall be taken as the distance between pallet beams, or back-calculated from,

$$
l_{e}=\pi \sqrt{\frac{E I}{N_{c r}}}
$$

where $N_{\mathrm{cr}}$ is the buckling load of the member obtained from an LBA with lateral restraints at all beam levels and $I$ is the second moment of area for the relevant axis of buckling.

The revised Standard contains guidelines for determining the effective length for torsional buckling under axial load for various types of brace-to-upright connections.

In these design approaches, torsion is considered in determining the design capacities $\left(N_{\mathrm{c}}, M_{\mathrm{bx}}, M_{\mathrm{by}}\right)$ whereas the design actions $\left(N^{*}, M_{\mathrm{x}}{ }^{*}, M_{\mathrm{y}}{ }^{*}\right)$ are determined from analyses which do not consider torsion. The implication of not considering torsion in the structural analysis is that moment amplification resulting from torsion is not accounted for. Whether torsion-induced moment amplification is significant will depend on whether the torsional buckling stress $\left(f_{\mathrm{oz}}\right)$ is lower or higher than the flexural buckling stress $\left(f_{\text {ox }}\right)$. If higher, torsion is unlikely to contribute to moment amplification. If lower, torsional buckling, by itself, produces bending about the $\mathrm{x}$-axis and hence amplification of the moment $M_{\mathrm{x}}{ }^{*}$. While the revised Standard does not require consideration of torsion-induced moment amplification, a conservative approach to account for this effect (for both LA and GNA) would be to (i) determine the flexural-torsional buckling stress $\left(f_{\text {oxz }}\right)$ by combining 
the flexural buckling stress $\left(f_{\text {ox }}\right)$ obtained from the LBA with the torsional buckling stress $\left(f_{\text {oz }}\right)$ based on an effective length determined from the provisions of the revised Standard, and (ii) calculating the critical load $\left(N_{\mathrm{cr}}\right)$ based on the flexural-torsional buckling stress, $N_{\mathrm{cr}}=f_{\text {oxz }} A$, in determining the amplification factor for $M_{\mathrm{x}}^{*}$.

Cold-formed rack structures usually feature semi-rigid or non-linear connections between uprights and pallet beams, and between the uprights and the support. The moment-rotation relationship for the connections shall be determined from testing (cantilever, portal sway and/or base plate tests as per the revised Standard) and implemented in the structural model. For design, it needs to be checked that the moment developing in the connection under factored limit state loads does not exceed the experimentally determined design capacity, which includes a resistance factor $(\phi)$ of 0.9 on the experimental characteristic capacity as per Clause 7.2.2 of the Standard. If LA is used as basis for design, the moment in the connections shall be amplified using the same amplification factor as for the moment in the upright.

The reduced shear stiffness of upright frames shall be considered in the structural model.

\section{Flexure and Torsion in LA and GNA}

When the LA and GNA include torsion, they may be assumed to be 3D, and the design actions are $\left(N^{*}, M_{\mathrm{x}}{ }^{*}, M_{\mathrm{y}}{ }^{*}, M_{\mathrm{z}}{ }^{*}\right)$ when warping torsion is not considered, and $\left(N^{*}, M_{\mathrm{x}}{ }^{*}, M_{\mathrm{y}}{ }^{*}, M_{\mathrm{z}}{ }^{*}, B^{*}\right)$ when warping torsion is considered, where $B^{*}$ is the bimoment. If obtained from an LA, moment amplification of the bending moments $\left(M_{\mathrm{x}}{ }^{*}, M_{\mathrm{y}}{ }^{*}\right)$ is required. However, amplification of the twisting moment $\left(M_{\mathrm{z}}{ }^{*}\right)$ can be expected to be small because it is associated with $2^{\text {nd }}$ order displacements in combination with shearing forces $\left(V_{\mathrm{x}}^{*}, V_{\mathrm{y}}^{*}\right)$, of which the latter are generally an order of magnitude smaller then the axial force $\left(N^{*}\right)$. Similarly, amplification of the bimoment $\left(B^{*}\right)$ 
can be expected to be small because the bimoment is associated with the warping torsion moment, which is not expected to be substantially amplified when the total twisting moment is not. It is therefore only required to amplify the bending moments $\left(M_{\mathrm{x}}{ }^{*}, M_{\mathrm{y}}{ }^{*}\right)$ when the design actions are determined from LA, irrespective of whether the analysis considers warping torsion or not.

The design approach is similar to when torsion is not considered in the analysis, i.e. (i) the effect of combined actions is accounted for using the biaxial interaction Equation (9), in which $\left(M_{\mathrm{x}}{ }^{*}, M_{\mathrm{y}}{ }^{*}\right)$ are maximum design actions in the span obtained from a GNA, or amplified design actions based on an LA; and (ii) the nominal member flexural capacities $\left(N_{\mathrm{c}}, M_{\mathrm{bx}}, M_{\mathrm{by}}\right)$ are determined in the same way as when torsion is not considered in LA and GNA.

It is not required to consider the twisting moment and the bimoment in the interaction equation because (i) the axial force $\left(N^{*}\right)$ and bending moments $\left(M_{\mathrm{x}}{ }^{*}, M_{\mathrm{y}}{ }^{*}\right)$ are not likely to be significantly altered by the inclusion of torsion in the analysis, and (ii) the design provisions for determining the nominal member flexural capacities $\left(M_{\mathrm{bx}}, M_{\mathrm{by}}\right)$ implicitly consider the presence of twisting moments $\left(M_{\mathrm{Z}}^{*}\right)$ and bimoments $\left(B^{*}\right)$, since these actions featured in the tests used for deriving the design strength curve.

The difference between including and not including torsion in the structural analysis is that moment amplification is more rationally dealt with in an analysis that considers torsion. It does not necessarily lead to higher design capacities. 


\section{GMNIAC}

For design to be based on GMNIAc, and hence be premised on beam element analysis, the crosssections must be compact for compression and bending as per AS4100, see Table 1. The analysis must consider torsion, except if the members have high torsional rigidity (e.g. are hollow) and 3D torsional effects can be shown to be insignificant.

The revised Standard allows the design check to be carried out in one of two ways:

1) In analogy with Appendix D of AS4100, the section capacity is checked using,

$$
\frac{N^{*}}{\phi N_{s}}+\frac{M_{x}^{*}}{\phi M_{s x}}+\frac{M_{y}^{*}}{\phi M_{s y}} \leq 1
$$

(or using higher tier interaction equations for compact I-sections and hollow sections), where $\phi=0.9$ according to AS4100. In eqn. (11), $N_{\mathrm{s}}$ is the section capacity for compression while $M_{\mathrm{sx}}$ and $M_{\mathrm{sy}}$ are the section capacities for bending about the principal $\mathrm{x}$ and $\mathrm{y}$-axes respectively, determined according to Section 5 of the Standard and accounting for the effects of local buckling and perforations. If the upright is subjected to primary torsion action, the following interaction equation shall be used,

$$
\frac{N^{*}}{\phi N_{s}}+\frac{M_{x}^{*}}{\phi M_{s x}}+\frac{M_{y}^{*}}{\phi M_{s y}}+\frac{B^{*}}{\phi B_{s}} \leq 1
$$

where the bimoment $\left(B^{*}\right)$ has been added to account for the effect of warping torsion. The bimoment section capacity $\left(B_{\mathrm{s}}\right)$ is conservatively calculated as,

$$
B_{s}=\frac{I_{w}}{\omega_{\max }} f_{y}
$$

where $I_{\mathrm{w}}$ is the warping rigidity, $\omega_{\max }$ is the maximum value of sectorial coordinate and $f_{\mathrm{y}}$ is the yield stress. 
2) The ultimate capacity of the frame is determined directly by advanced analysis. In this case, the factored ultimate limit states loads are multiplied by a load increment factor $(\lambda)$, which is increased until the frame fails at $\lambda=\lambda_{\max }$. Based on nominal values, the frame can support the ultimate loads if $\lambda_{\max } \geq 1$, and fails if $\lambda_{\max }<1$. To account for random variabilities, the resistance factor of the system is taken as $\phi_{\mathrm{s}}=0.9$, which is the same as the resistance factor used for members in AS4100.

Consequently, the design is carried out by checking that according to the advanced analysis, the ultimate capacity of the frame is reached for,

$$
\phi_{s} \lambda_{\max } \geq 1 \quad \Rightarrow \quad \lambda_{\text {max }} \geq \frac{1}{\phi_{s}}
$$

where $\phi_{\mathrm{s}}=0.9$.

Choosing an appropriate system resistance factor requires a comprehensive study of the system reliability of steel storage rack structures, which is not available at present. For statically redundant frames like conventional steel storage racks, it is most likely conservative to use the member resistance factor for the resistance factor of the system (Ellingwood 1994; Ellingwood 2000). A recent study (Rasmussen and Gilbert 2011) on the down-aisle strength of braced and unbraced steel storage racks has shown that on an average basis, strengths obtained using GMNIAc and GMNIAs analyses match the strengths obtained using LA and GNA analyses, although differences in strengths are observed when considering braced and unbraced frames separately.

For both design check options, the semi-rigid characteristics of the pallet beam-to-upright and base plate connections shall be included in the structural model, and it shall be checked that the design values of connection strength, which must include a capacity factor $(\phi)$ as per Clause 7.2.2 of the Standard, are not exceeded under the action of the ultimate limit states loads. It shall also be checked that the displacements of the structure do not exceed the deformation limits under service loads. 
The reduced shear stiffness of upright frames shall be considered in the structural model as obtained from tests described in the revised Standard, or the connections between uprights and diagonal brace members shall be accurately modeled to include the flexibility in these connections leading to the reduced shear stiffness of the upright frames, e.g. see Koen (2008) for details.

\section{GMNIAs}

GMNIAs assumes non-compact or slender cross-sections, and hence discretisation of the crosssection (e.g. into shell elements) is required. Frame, member and cross-sectional (local and distortional) geometric imperfections are required to be included in the structural model, as described under Geometric imperfections, residual stresses and notional horizontal forces, as are perforations. The ultimate capacity of the frame is determined directly by advanced analysis, as for GMNIAc Design Option (2), i.e. Equation (14) must be satisfied.

Connections may be modeled in one of two ways:

1) All components of the connections are discretised and modeled explicitly, e.g. beam end brackets may be modeled using shell elements, bolts may be modeled using beam elements, etc. Where the connection relies on friction, contact elements may be required.

The structural model shall be verified against connection tests conducted as per the revised Standard. The model shall be shown to replicate the experimentally obtained moment-rotation behaviour and strength.

2) The connections are modeled as nonlinear beam or connection elements, as in LA, GNA or GMNIAc. In this case, it may be required to insert solid elements in the members near the connections, allowing the connection elements to be inserted between these. The connection 
elements shall incorporate the experimentally obtained moment-rotation relationships, which shall be scaled down by a capacity factor $(\phi)$, and it shall be checked that the design value of the experimentally obtained connection strength is not exceeded. Particular attention needs to be paid to the modeling of continuity/support conditions for the warping displacement at connection points.

The reduced shear stiffness of upright frames derived from the flexibility of the connections between the uprights and diagonal bracing members shall be considered in the structural model or modeled directly as for GMNIAc.

\section{Design Provisions for (Doubly Symmetric) Hot-rolled Steel Uprights}

\section{General}

Heavily loaded racks may be constructed from hot-rolled (or fabricated) I-sections or tubular sections, the latter being cold-formed or hot-rolled. Collectively, these sections will be referred to as "hot-rolled". They share the common characteristic of being doubly symmetric and may be designed to AS4100. Accordingly, the flexural section capacity may reach the plastic moment.

\section{Buckling modes}

Being doubly symmetric cross-sections, the critical buckling modes for compression are flexural modes. The torsional buckling load is generally higher than the flexural buckling loads for Isections and hollow sections and needs not be considered. For bending, flexural-torsional buckling may occur for I-sections in major $\mathrm{x}$-axis bending, while I-sections bent about the minor $\mathrm{y}$-axis and tubular sections bent about any axis will fail by yielding. 


\section{LA and GNA}

The design approach described for cold-formed sections applies except that only flexure (and not torsion) needs to be considered in determining $N_{\mathrm{c}}$ and $M_{\mathrm{by}}$.

\section{GMNIAC}

The design approach described for cold-formed sections applies. If the frame consists of tubular uprights, it is not necessary to consider the bimoment $\left(B^{*} / B_{\mathrm{s}}\right)$ in the failure criterion for the case of primary torsional action.

\section{GMNIAs}

The design approach described for cold-formed sections applies except that the cross-section is not prone to distortional buckling and geometric imperfections in this mode need not be considered.

\section{Validation of Structural Analysis Programs}

The revised Standard requires structural analysis programs used to perform LA, LBA, GNA, GMNIAc and GMNIAs to be validated against benchmark analytical solutions, well-documented experimental tests, or similar. Thus the onus is on the designer to check that software used for design has been adequately checked, e.g. finite elements (or strips) used for the structural analysis shall be shown to pass the patch test and/or benchmark tests relevant to thin-walled structural 
frames. Likewise, the onus is on the designer to perform convergence studies to demonstrate the adequacy of the density of the finite element mesh used for the structural modeling.

Guidance on the finite element modeling of steel frames composed of slender cross-sections may be found in Bakker and Pekoz (2003) and Sarawit et al. (2003).

\section{Conclusions}

This paper summarises the main analysis and design provisions of the recently revised Australian Standard for steel storage racks (AS4084 2012). The revised standard allows the design to be based on analysis types ranging from linear analysis to advanced geometric and material nonlinear analysis with imperfections (GMNIA). Two types of GMNIA are allowed in the revised standard, namely the analysis of structural frames with compact cross-sections (GMNIAc) and the analysis of frames with non-compact or slender cross-sections (GMNIAs). Provisions are included for the frame, member and cross-section geometric imperfections to be incorporated in the structural model.

When based on GMNIA, it is possible to carry out the design without reference to a structural steel standard. For this case, the revised Standard specifies a system resistance factor of $\phi_{\mathrm{s}}=0.9$, and requires that the load factor on the ultimate limit states loads exceeds $1 / \phi_{\mathrm{s}}$ in determining the ultimate strength of the frame. The revised Standard permits the design of storage racks failing in 3D modes by GMNIA, provided flexural and torsional member displacements as well as local and distortional deformations are modeled, as appropriate. 


\section{Acknowledgments}

The authors gratefully acknowledge the constructive comments to this paper offered by Professors Nick Trahair and Greg Hancock.

\section{References}

AISC (2005). Specification for Structural Steel Buildings, ANSI/AISC 360-05. Chicago, American Institute of Steel Construction.

AISC (2010). Specification for Structural Steel Buildings, ANSI/AISC 360-10. Chicago, American Institute of Steel Construction.

AS4084 (1993). Steel Storage Racking. Sydney, Standards Australia.

AS4084 (2012). Steel Storage Racking. Sydney, Standards Australia.

AS4100 (1998). Steel Structures, AS4100. Sydney, Standards Australia.

AS/NZS4600 (2005). Cold-formed Steel Structures, AS/NZS 4600. Sydney, Standards Australia.

Bakker, M. and Pekoz, T. (2003). "The Finite Element Method for Thin-walled Members - Basic

Principles." Thin-walled Structures 41: 179-189. 
Clarke, M. J., Bridge, R. Q., Hancock, G. J. and Trahair, N. S. (1992). "Advanced analysis of steel building frames." Journal of Constructional Steel Research 23(1-3): 1-29.

Clarke, M. J., Bridge, R. Q., Hancock, G. J. and Trahair, N. S. (1993). Benchmarking and Verification of Second-Order Elastic and Inelastic Frame Analysis Programs. Plastic hinge based methods for advanced analysis and design of steel frames - an assessment of the state of the art. D. W. White and W. F. Chen. Bethlehem, PA, Structural Stability Research Council.

Davies, M. J. (2002). "Second-Order Elastic-Plastic Analysis of Plane Frames." Journal of Constructional Steel Research 58: 1315-1330.

Ellingwood, B. R. (1994). "Probability-based Codified Design: Past Accomplishments and Future Challenges." Structural Safety 13: 159-176.

Ellingwood, B. R. (2000). "LRFD: Implementing Structural Reliability in Professional Practice." Engineering Structures 22: 106-115.

EN1993-1-1 (2005). Eurocode 3: Design of steel structures Part 1-1: General rules and rules for buildings. Brussels, European Committee for Standardisation.

EN1993-1-5 (2006). Eurocode 3: Design of steel structures Part 1-5: Plated structural elements. Brussels, European Committee for Standardisation.

EN1993-1-6 (2007). Eurocode 3: Design of steel structures Part 1-6: Strength and Stability of Sheel Structures. Brussels, European Committee for Standardisation. 
EN15512 (2009). Steel Static Storage Systems - Adjustable Pallet Racking - Principles for Structural Design. Brussels, European Committee for Standardisation.

Gilbert, B. P. (2009). The Behaviour of Steel Drive-in Racks under Static and Forklift Truck Impact Forces, $\mathrm{PhD}$ thesis, School of Civil Engineering, University of Sydney.

Gilbert, B. P. and Rasmussen, K. J. R. (2011). Determining the Transverse Shear Stiffness of Steel Storage Rack Upright Frames. 6th International Conference on Thin-walled Structures, ICTWS6. Eds. D. Dubina \& V. Ungureanu. Timisoara: 821-828.

Horne, M. (1985). Frame Instability and the Plastic Design of Rigid Frames. Steel Framed Structures - Stability and Strength. R. Narayanan. London, Elsevier Applied Science: 1-29.

Koen, D. (2008). Structural Capacity of Light Gauge Steel Storage Rack Uprights. MPhil thesis, School of Civil Engineering, University of Sydney.

Lecce, M. and Rasmussen, K.J.R. (2006), "Distortional Buckling of Cold-Formed Stainless Steel Sections: Finite-Element Modeling and Design", Journal of Structural Engineering, ACSE 132(4): 505-514.

NAS (2007). North American Specification for the Design of Cold-Formed Steel Structural Members. Washington DC, American Iron and Steel Institute.

Nethercot, D. A. (2000). "Frame Structures: Global Performance, Static and Stability Behaviour General Report." Journal of Constructional Steel Research 55(1-3): 109-124. 
Papangelis, J. P. and Hancock, G. J. (1995). "Computer Analysis of Thin-Walled Structural Members." Computers and Structures 56(1): 157-176.

Rasmussen, K. J. R. and Gilbert, B. P. (2011). "Analysis-based 2D design of steel storage racks." International Journal of Structural Stability and Dynamics 5(1): 929-947.

RMI (2008). Specification for the Design, Testing, and Utilization of Industrial Steel Storage Racks. Charlotte, Rack Manufacturers Institute.

Sarawit, A. T., Kim, Y., Bakker, M. C. M. and Pekoz, T. (2003). "The Finite Element Method for Thin-walled Members - Applications." Thin-walled Structures 41: 191-206.

Sarawit, A. T. and Pekoz, T. (2006). Direct Analysis Method for Industrial Steel Storage Racks. Ithaca, Cornell University

Schafer, B. (2008). CUFSM: elastic buckling analysis of thin-walled members by the finite strip method. Version 3.12, www.ce.jhu.edu/bschafer/cufsm/, Johns Hopkins University.

Surovek-Maleck, A. E. and White, D. W. (2004). "Alternative Approaches for Elastic Analysis and Design of Steel Frames. I: Overview." Journal of Structural Engineering, ASCE 130(8): 1186-1196.

Walker, A. (1975). Design of Struts. Design and Analysis of Cold-formed Sections. A. Walker. London, International Textbook Company. 
White, D. W., Surovek, A. E., Alemdar, B. N., Chang, C.-J., Kim, Y. D., and Kuchenbecker, G. H. (2006). "Stability Analysis and Design of Steel Building Frames Using the 2005 AISC Specification." International Journal of Steel Structures: 71-91.

Yang D. and Hancock, G. J. (2004), “Compression Tests of Cold-Reduced High Strength Steel Sections. I: Stub Columns”, Journal of Structural Engineering, ACSE 130(11): 1772-1781.

Yang D. and Hancock, G. J. (2006), "Numerical Simulation of High-Strength Steel Box-Shaped Columns Failing in Local and Overall Buckling Modes”, Journal of Structural Engineering, ACSE 132(4): 541-549.

Ziemian, R. D. and McGuire, W. (2002). "Modified Tangent Modulus Approach, a Contribution to Plastic Hinge Analysis." Journal of Structural Engineering, ASCE 128(10): 1301-1307.

Ziemian, R. D., McGuire, W. and Deierlein, G. G. (1992). "Inelastic Limit States Design. Part I: Planar Frame Studies." Journal of Structural Engineering, ACSE 118(9): 2532-2549. 